\title{
Magnitude of institutional delivery service utilization and associated factors among women in pastoral community of Awash Fentale district Afar Regional State, Ethiopia
}

\author{
Luelseged Assefa ${ }^{1}$, Mussie Alemayehu ${ }^{2}$ and Ayal Debie ${ }^{3 *}$
}

\begin{abstract}
Objective: Reduction of maternal mortality is a global priority particularly in developing countries like Ethiopia where maternal mortality ratio is one of the highest in the world. Most deliveries in developing countries occur at home without skilled birth attendants. Therefore, the objective of this study was to assess institutional delivery service utilization and associated factors among women in pastoral community of Awash Fentale district, Ethiopia.

Results: Overall, 35.2\% of women delivered at health facilities. Women who had good knowledge AOR $=2.1,95 \% \mathrm{Cl}$ $1.32,4.87)$, Ante Natal Care (ANC) follow up ( $\mathrm{AOR}=3.2,95 \% \mathrm{Cl} 1.55,6.63)$, resided in a place where distance to reach at the nearby health facilities takes $<30 \mathrm{~min}(\mathrm{AOR}=3.1 ; 95 \% \mathrm{Cl} 2.57,66.33)$ and women whose husband involved in decision regarding delivery place ( $\mathrm{AOR}=1.9 ; 95 \% \mathrm{Cl} 1.49,5.07$ ) were more likely to deliver at health facility. Therefore, strengthening ANC services, improving maternal knowledge, involving husbands in decision of delivery place and expanding health facilities in the community would enhance institutional delivery.
\end{abstract}

Keywords: Institutional delivery, Awash Fentale district, Pastoral community, Afar region

\section{Introduction}

Delivery attended by qualified health care providers is the best strategy in reducing maternal mortality in the world and one of the indicators to track national effort towards safe motherhood [1]. Maternal mortality ratio in Ethiopia is among the highest in sub-Saharan Africa which was 676 per 100,000 live births as a result of low maternal service utilization particularly low institutional delivery [2]. Skilled delivery is low in southern Asia and sub-Saharan Africa (SSA) which is 40 and $47 \%$, respectively [3]. Institutional delivery is also low in Ethiopia ranged from 4.1 to $18.2 \%$ of women gave birth at health facilities [4-6]. In Afar region, $93.6 \%$ of mothers give birth at home which is one of the highest home delivery practices among the nine regions of Ethiopia [7].

\footnotetext{
*Correspondence: debieayal@gmail.com

${ }^{3}$ Department of Health Service Management and Health Economics,

University of Gondar, P.o.Box: 196, Gondar, Ethiopia

Full list of author information is available at the end of the article
}

Institutional delivery ensures safe birth, reduces occurrence of complication during delivery and immediately after birth and increases the survival of mothers and newborns $[8,9]$. However, majority of deliveries in Ethiopia particularly in pastoral community of Afar region occur at home without skilled birth attendants. This is because; in the region nomads are moving seasonally from place to place for the purpose of feeding and getting water for their cattle. Hence mothers may not have access to health facilities in the nearby $[7,10,11]$. Therefore, recognizing factors affecting institutional delivery service utilization in pastoral community has paramount importance in order to design a strategy for enhancing institutional delivery service utilization. Accordingly, this study was intended to assess magnitude of institutional delivery service utilization and associated factors among reproductive age women in pastoral community of Awash Fentale district, Ethiopia. 


\section{Main text Methods}

A community based cross-sectional study was employed among women of childbearing age group (15-49 years) in Pastoral community of Awash Fentale district who gave birth in the last 1 year preceding the study. The district has 5 rural kebeles with a total population of 29,076 within 5101 households. The total number of reproductive age women (15-49 years) also estimated to be 4035 [12]. The study was conducted from February to May, 2016. The source and study populations were all women with a child of less than 12 months old from all rural kebeles of the district. All mentally capable women (conscious and free from a known psychiatric disorder) with a child less than 12 months and resided in the respective kebeles at least for the past 6 months were included in the study while mothers who were unable to communicate and seriously ill were excluded from the study.

Sample size was calculated by using both single and double population proportion formula. Sample size for first objective was calculated by using single population proportion formula with an assumption: $\mathrm{Za} / 2$ at $95 \%$ confidence level $= \pm 1.96$, margin of error $(\mathrm{w})=3 \%$, and proportion $(\mathrm{P})=6.4 \%$ [7], design effect $=1.5$ and non response rate $=10 \% . \mathrm{N}=\left(\mathrm{Z} a_{/ 2}\right)^{2}(\mathrm{P})(1-\mathrm{P}) /(w)^{2}=(1.96)^{2}$ (0.064) $(0.936) /(0.03)^{2}=256$; after adding $10 \%$ non response rate it became 282 . The final sample size for this objective after multiplying by design effect 1.5 was 423 . Sample size for second objective was calculated by using double population proportion formula by using significantly associated variables from the previous study with an assumption of power $=80 \%, 95 \%$ level of confidence, design effect $=1.5$. The identified variables were history of ANC follow up, mothers' residence, mothers' educational status and wealth status $[11,13,14]$. The final sample sizes for this objective based on these factors were $96,53,376$, and 53, respectively. Using the largest sample size is more appropriate for maintaining sample size adequacy. Therefore, the final sample size was decided to be 423. During selection of study participants, first the sample size was proportionally allocated to each selected kebeles and finally, cluster sampling technique was used to select mothers.

The dependent variable of the study was institutional delivery service utilization. The independent variables were socio-demographic characteristics (age, religion, level of education, marital status, mothers and husband occupation, and level of income); previous obstetric history of mothers (gravidity, parity, abortion and still birth/ intrauterine fetal death); health seeking related factors (women's knowledge, attitude, perception, decision making power on place of delivery), and accessibility related factors (transportation and time spent to reach at health facility). The knowledge of mothers on pregnancy and labor was measured by using 9 questions and those mothers who scored $50 \%$ and above of the knowledge related questions were considered to have good knowledge and those mothers scored below $50 \%$ of the knowledge related questions were considered to have poor knowledge. Whereas, the attitude of mothers towards institutional delivery was measured by using 9 questions and those mothers who scored on 50\% and above of the attitude related questions were considered to have favorable attitude and those mothers scored below $50 \%$ of the attitude measurement questions were considered to have unfavorable attitude.

A structured questionnaire, adopted from different literatures, was used for data collection $[7,11,15,16]$. The questionnaire was first prepared in English and then, translated to the local language. Finally, it was back to English in order to ensure consistency. The data collectors and supervisors were trained for 2 days mainly on the objectives of the study and on the basic techniques of the interviewing process. The questionnaire was pretested on 21 child bearing age women in the rural kebele of Kurkura in Amibara district. Unclear, misunderstood or ambiguous words or questions were modified based on the pretest findings. Supervisors and the principal investigators checked the completeness and consistency of the questionnaire on daily bases in order to ensure the data quality. The collected data were checked for completeness and consistency and entered into EPI info version 3.5.3 and exported to SPSS version 20 for analysis. Descriptive statistics such as frequency and percentage were presented by using tables and graphs. Logistic regression analysis was carried out to identify factors associated with institutional delivery service utilization. Those independent variables having $\mathrm{P}$ value less than 0.2 during bivariate analysis were included in the multivariable analysis. Crude and adjusted Odds ratios (OR) with $95 \% \mathrm{CI}$ and $\mathrm{P}$ value $<0.05$ were used to identify the strength and level of significance of the association.

\section{Results}

\section{Socio-demographic characteristics of women}

A total of 423 mothers participated in the study with a response rate of $100 \%$. The mean age of respondents was $28.84 \pm 6.55$ years, and the median age of women was 29 years. From all study participants, $50 \%$ of the respondents were Afar in their ethnicity, $94.6 \%$ were currently married and $60.8 \%$ were Muslim religion followers. From all currently married mothers, $68 \%$ of the respondents' husbands were unable to read and write and $60 \%$ of mothers were unable to read and write. Out of the total participants, $12.8 \%$ were housewife, and $62 \%$ of their husbands' were pastoralist. $47.8 \%$ of respondents their 
monthly household income was in the range of 500-1000 Ethiopian Birr (ETB) (Table 1).

\section{Obstetrics characteristics of women}

Among the study participants, $76.4 \%$ of mothers got married before the age of 20 years and $67.6 \%$ who gave the recent birth were in age range of 20-34 years. From all respondents, $77.3 \%$ of women attended Ante Natal

Table 1 Socio-demographic characteristics of respondents in Awash Fentale district, Afar region, $2016(\mathrm{~N}=423)$

\begin{tabular}{|c|c|c|}
\hline Characteristics & Frequency & Percentage (\%) \\
\hline \multicolumn{3}{|l|}{ Age of women $(n=423)$} \\
\hline $15-19$ & 61 & 14.4 \\
\hline $20-24$ & 54 & 12.8 \\
\hline $25-29$ & 110 & 26.0 \\
\hline $30-34$ & 107 & 25.3 \\
\hline $35-39$ & 63 & 14.9 \\
\hline$\geq 40$ & 32 & 7.6 \\
\hline \multicolumn{3}{|l|}{ Religion ( $n=423$ ) } \\
\hline Muslim & 257 & 60.8 \\
\hline Christian & 166 & 39.2 \\
\hline \multicolumn{3}{|l|}{ Ethnicity ( $\mathrm{n}=423$ ) } \\
\hline Afar & 211 & 49.9 \\
\hline Oromo & 45 & 10.6 \\
\hline Tigray & 16 & 3.8 \\
\hline Amhara & 66 & 15.6 \\
\hline Others & 85 & 20.1 \\
\hline \multicolumn{3}{|l|}{ Women occupation $(n=423)$} \\
\hline House wife & 54 & 12.8 \\
\hline Farmer & 75 & 17.7 \\
\hline Employed & 10 & 2.4 \\
\hline Merchant & 33 & 7.8 \\
\hline Pastoralist & 251 & 59 \\
\hline \multicolumn{3}{|l|}{ Husband occupation( $(n=413)$} \\
\hline Pastoralist & 257 & 62 \\
\hline Farmer & 82 & 19.9 \\
\hline Employed & 43 & 10.4 \\
\hline Daily labor & 20 & 5 \\
\hline Merchant & 11 & 2.7 \\
\hline \multicolumn{3}{|c|}{ Monthly household income ETB ( $n=423$ ) (birr) } \\
\hline$<500$ & 36 & 8.5 \\
\hline $500-1000$ & 202 & 47.8 \\
\hline$>1000$ & 185 & 43.7 \\
\hline \multicolumn{3}{|c|}{ Maternal educational status $(n=423)$} \\
\hline Unable to read and write & 252 & 60 \\
\hline Primary school & 121 & 29 \\
\hline Secondary and above & 50 & 12 \\
\hline \multicolumn{3}{|c|}{ Husband educational status $(n=413)$} \\
\hline Unable to read and write & 281 & 68 \\
\hline Primary school & 68 & 16.1 \\
\hline Secondary school and above & 67 & 16.9 \\
\hline
\end{tabular}

Care (ANC) during the last pregnancy. Out of all mothers, $64.5 \%$ of them had two to three live children, $2.8 \%$ had history of intra uterine fetal death (IUFD) or still birth and $6.6 \%$ had history of abortion. $45.2 \%$ of study participants were given Tetanus Toxoid (TT) vaccination twice before birth and $76.1 \%$ of mothers faced obstetric complication during their previous delivery (Table 2, Additional file 1: Figure S1; Additional file 2: Figure S2).

Table 2 Obstetric characteristics of respondents in pastoral Awash Fentale district, Afar region, $2016(\mathrm{~N}=423)$

\begin{tabular}{|c|c|c|}
\hline Characteristics & Frequency & Percentage (\%) \\
\hline \multicolumn{3}{|c|}{ Age at first marriage $(n=423)$ (years) } \\
\hline$<20$ & 323 & 76.4 \\
\hline$\geq 20$ & 100 & 23.6 \\
\hline \multicolumn{3}{|c|}{ Women's age during recent birth ( $n=423$ ) (years) } \\
\hline$<20$ & 42 & 9.9 \\
\hline $20-34$ & 286 & 67.6 \\
\hline $35-49$ & 95 & 22.5 \\
\hline \multicolumn{3}{|l|}{ Gravidity $(n=423)$} \\
\hline One & 63 & 14.9 \\
\hline Two to three & 115 & 27.2 \\
\hline Four to five & 121 & 28.6 \\
\hline$\geq \operatorname{Six}$ & 124 & 29.2 \\
\hline \multicolumn{3}{|l|}{ Parity $(n=423)$} \\
\hline One & 66 & 15.6 \\
\hline Two-three & 116 & 27.4 \\
\hline Four to five & 118 & 27.9 \\
\hline$\geq \operatorname{six}$ & 123 & 29 \\
\hline \multicolumn{3}{|c|}{ ANC follow up during last pregnancy $(n=423)$} \\
\hline Yes & 327 & 77.3 \\
\hline No & 96 & 22.7 \\
\hline \multicolumn{3}{|c|}{ Number of child alive $(n=423)$} \\
\hline One & 3 & 0.7 \\
\hline Two to three & 273 & 64.5 \\
\hline$\geq$ Four & 147 & 34.8 \\
\hline \multicolumn{3}{|c|}{ History of IUFD/still birth $(n=423)$} \\
\hline No & 411 & 97.2 \\
\hline Yes & 12 & 2.8 \\
\hline \multicolumn{3}{|c|}{ History of abortion $(n=423)$} \\
\hline No & 395 & 93.4 \\
\hline Yes & 28 & 6.6 \\
\hline \multicolumn{3}{|c|}{ Tetanus toxoid vaccination before birth $(n=423)$} \\
\hline Not at all & 74 & 17.5 \\
\hline Once & 23 & 5.5 \\
\hline Twice & 191 & 45.2 \\
\hline Three and more & 135 & 32 \\
\hline \multicolumn{3}{|c|}{ Obstetric complication during previous delivery $(n=423)$} \\
\hline Yes & 322 & 76.1 \\
\hline No & 101 & 23.9 \\
\hline
\end{tabular}




\section{Factors associated with institutional delivery service} utilization

Mothers who had good knowledge on institutional delivery service utilization were 2.1 times $(\mathrm{AOR}=2.1$; $95 \% \mathrm{CI}$ $1.32,4.87)$ more likely to use institutional delivery service as compared to those women having poor knowledge.

Women who were attending Antenatal Care follow up during last pregnancy were 3.2 times $(\mathrm{AOR}=3.2$; $95 \% \mathrm{CI}$ $1.55,6.63)$ more likely to deliver at health facilities than women who did not attend ANC.

Women who had to travel $30 \mathrm{~min}$ to reach at the nearby health facilities were 3.1 times $(\mathrm{AOR}=3.1$; 95\% CI 2.57, 66.33) more likely to deliver at health facility as compared to those women who had to travel more than $30 \mathrm{~min}$ to reach to the nearby health facilities.

Women whose husband involved in decision regarding place of delivery were 1.9 times (AOR $=1.9 ; 95 \%$ CI 1.49 , 5.07) more likely to deliver at health facility as compared to women whose husband did not involve in the decision making process of their delivery place (Table 3 ).

\section{Discussion}

The magnitude of institutional delivery service utilization in the study area was $35.2 \%$. However, the remaining $64.8 \%$ of women gave birth at their homes. This study was comparable with a study conducted in Ghana (37.5\%) [17], and it is lower than the studies conducted in other parts of Ethiopia such as Bahir Dar (78.8\%) [18], Woldia (48.3\%) [19], Tigray (59\%), Diredawa (59\%), Addis Ababa (79\%) [2], Tigray (57\%) and Addis Ababa (97\%) [20]; and Tanzania (74.5\%) [21]. However, it is higher than findings of the studies conducted in other parts of Ethiopia such as Munisa (12.3\%) [13], Sekela (12.1\%) [22], Dodota (18.2\%) [5], rural Jimma Horro (8\%) [23], Banja (15.7\%) [24] and mini-EDHS 2014 report of Ethiopia (16\%) [7], EDHS 2011 report of Ethiopia (10\%) [2] and EDHS 2016 report of Ethiopia (26\%) [10]. This might be due to difference in study area, period, and study participants. Difference in health facilities' infrastructure might affect mothers' institutional delivery service utilization. Health facilities which had maternal waiting home and presence of ambulance service might also give a chance for women to attend institutional delivery.

In this study, those mothers who had history of ANC follow up were 3.2 times more likely $(\mathrm{AOR}=3.2 ; 95 \% \mathrm{CI}$ $1.55,6.63)$ attend institutional delivery than mothers who had no history of ANC follow up. This finding was supported by a study conducted in Munisa, Sekela and Western Ethiopia [13, 22, 26]; Tanzania [21], Ghana [17], and Nigeria [25]. The possible explanation might be mothers who decide to attend institutional delivery as a result of the information they got during their prenatal care.
Table 3 Factors associated with institutional delivery service utilization among women in pastoral Awash Fentale district, 2016

\begin{tabular}{|c|c|c|c|c|}
\hline \multirow[t]{2}{*}{ Variables } & \multicolumn{2}{|c|}{$\begin{array}{l}\text { Institu- } \\
\text { tional } \\
\text { delivery }\end{array}$} & \multirow{2}{*}{$\begin{array}{l}\text { COR } \\
(95 \% \mathrm{Cl})\end{array}$} & \multirow{2}{*}{$\begin{array}{l}\text { AOR } \\
(95 \% \mathrm{Cl})\end{array}$} \\
\hline & Yes & No & & \\
\hline \multicolumn{5}{|c|}{ Age of respondent } \\
\hline $15-19$ & 17 & 44 & 1 & 1 \\
\hline $20-34$ & 85 & 182 & $1.2(0.65,2.24)$ & $1.1(0.53,2.33)$ \\
\hline$\geq 35$ & 47 & 48 & $2.5(1.27,5.05)$ & $2.1(0.88,4.85)$ \\
\hline \multicolumn{5}{|l|}{ ANC follow up } \\
\hline Yes & 134 & 193 & $3.7(2.07,6.79)$ & $3.2(1.55,6.63)^{*}$ \\
\hline No & 15 & 81 & 1 & 1 \\
\hline \multicolumn{5}{|c|}{ Distance to health facility (min) } \\
\hline$\leq 30$ & 126 & 213 & $1.6(0.83,50.95)$ & $3.1(2.57,66.33)^{*}$ \\
\hline$>30$ & 23 & 61 & 1 & 1 \\
\hline \multicolumn{5}{|c|}{ Attitude of women } \\
\hline Favorable & 137 & 214 & $3.2(0.12,12.14)$ & $1.2(0.28,2.98)$ \\
\hline Unfavorable & 12 & 60 & 1 & 1 \\
\hline \multicolumn{5}{|c|}{ Knowledge of women } \\
\hline Good & 75 & 28 & $8.8(1.58,13.32)$ & $2.1(1.32,4.87)^{*}$ \\
\hline Poor & 74 & 244 & 1 & 1 \\
\hline \multicolumn{5}{|c|}{ Husband involved on decision of delivery place } \\
\hline Yes & 62 & 80 & $1.7(0.91,2.86)$ & $1.9(1.49,5.07)^{*}$ \\
\hline No & 87 & 194 & 1 & 1 \\
\hline
\end{tabular}

* Significant at $P$ value $<0.05$

Women who had to travel $30 \mathrm{~min}$ to reach at the nearby health facilities were 3.1 times (AOR $=3.1$; 95\% CI 2.57, 66.33) more likely to deliver at health facility as compared to those women who had to travel more than $30 \mathrm{~min}$ to reach to the nearby health facilities. This finding was consistent with the study conducted from Western Ethiopia and Dembecha district $[26,27]$. This might be due to mothers resided to the nearby health institutions might have different access of maternal health services such as health education and ANC services. Moreover, mothers who resided to the nearby health facilities had no problem of transportation to attend institutional delivery at any time. In addition, in pastoral community most of husbands and adult male family members were seasonally moving from place to place to fed and get water for their cattle and it results mothers couldn't get any support to take them to health facilities during the time of labor.

Those women who had good knowledge about attending health facility delivery were 2.1 times more likely (AOR $=2.1 ; 95 \%$ CI 1.32, 4.87) to deliver at health facilities when compared with women who had poor knowledge. This finding was in line with the study conducted at 
Sekela district and Western Ethiopia [22, 26]. This might be due to those women who had good knowledge might have high attitudinal change towards institutional delivery. This may help pregnant mothers to predict bad delivery outcomes. The other justification might be mothers having good knowledge may not be relatively affected by traditional malpractices and/or beliefs such as they might not consider mothers delivered at home as a hero of the community. Furthermore, knowledgeable mothers might be highly influential on their husbands and/or other relatives to take them to health facility while they were in labor.

Women whose husband involved in decision of delivery place were 1.9 times more likely $(\mathrm{AOR}=1.9 ; 95 \% \mathrm{CI}$ $1.49,5.07)$ deliver at health facility than women's husband who did not involve. This study finding was consistent with the study conducted at Dodota district [5].This might be due to male dominancy was common in pastoral community. However, husbands involved in maternal obstetric services during their pregnancy would decide in better way to attend their wives' childbirth at health facility. Generally, this study finding revealed that majority of mothers still delivered at home. Therefore, strengthening ANC services, improving maternal knowledge, involving husbands in decision regarding delivery place and expanding health facilities to the nearby the community would enhance institutional delivery. Ministry of Health $(\mathrm{MOH})$ and Regional Health Bureaus had better to use this study finding for policy making in the case of pastoral community throughout the country.

\section{Limitations}

- Mothers might lead to a recall bias due to data was collected from mothers about their experience since 1 year back and.

- The study could not allow cause effect relationship because of its cross sectional nature.

\section{Additional files}

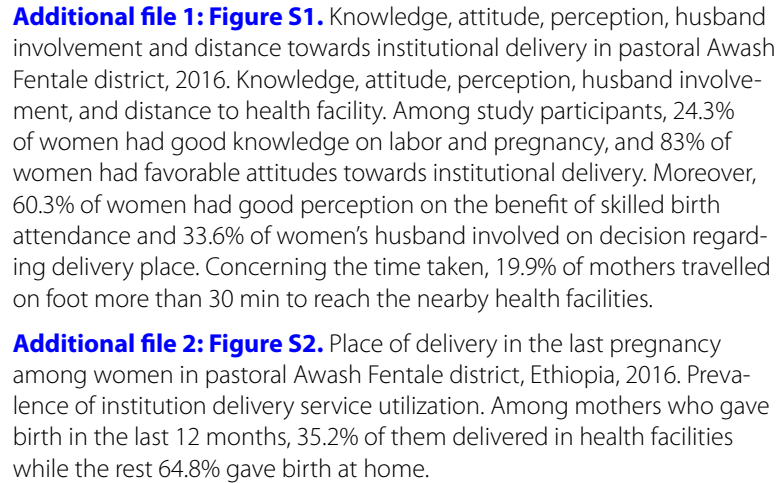

Additional file 1: Figure S1. Knowledge, attitude, perception, husband involvement and distance towards institutional delivery in pastoral Awash Fentale district, 2016. Knowledge, attitude, perception, husband involvement, and distance to health facility. Among study participants, $24.3 \%$ of women had good knowledge on labor and pregnancy, and $83 \%$ of women had favorable attitudes towards institutional delivery. Moreover, $60.3 \%$ of women had good perception on the benefit of skilled birth attendance and $33.6 \%$ of women's husband involved on decision regarding delivery place. Concerning the time taken, $19.9 \%$ of mothers travelled on foot more than $30 \mathrm{~min}$ to reach the nearby health facilities.

Additional file 2: Figure S2. Place of delivery in the last pregnancy among women in pastoral Awash Fentale district, Ethiopia, 2016. Prevalence of institution delivery service utilization. Among mothers who gave birth in the last 12 months, 35.2\% of them delivered in health facilities while the rest $64.8 \%$ gave birth at home.

\section{Abbreviations}

ARHB: Afar Regional Health Bureau; ANC: Ante Natal Care; EMDHS: Ethiopia Mini Demographic Health Survey; HD: Home Delivery; HIV: Human Immune Virus; IMR: Infant Mortality Rate; IUFD: Intra Uterine Fetal Death; ID: Institutional Delivery; MMR: Maternal Morality Ratio; PMR: Perinatal Mortality Rate; TBAs: Traditional Birth Attendants; WHO: World Health Organization.

\section{Authors' contributions}

LA conceived the study, developed the tool, coordinated the data collection activity, and carried out the statistical analysis. MA participated in the design of the study, development of the tool, and drafting of the manuscript. AD participated in the design of the study and development of the tool, performed statistical analysis and drafted the manuscript. All authors read and approved the final manuscript.

\section{Authors' information}

LA is MPH and working in Afar Regional Health Bureau as Family Health Coordinator, Samara, Ethiopia. MA is an Assistant Professor of Public Health Reproductive Health and working as a lecturer in the Department of Reproductive Health, College of Medicine and Health Sciences, Mekelle University, Ethiopia. $\mathrm{AD}$ is MPH and working as a lecture in the Department of Health Service Management \& Health Economics, College of Medicine and Health Sciences, University of Gondar, Ethiopia.

\section{Author details}

${ }_{1}^{1}$ Afar Regional Health Bureau, Afar National Regional State, Samara, Ethiopia. ${ }^{2}$ Department of Reproductive Health, Mekelle University, Mekelle, Ethiopia.

${ }^{3}$ Department of Health Service Management and Health Economics, University of Gondar, P.o.Box: 196, Gondar, Ethiopia.

\section{Acknowledgements}

Authors would like to thank all respondents for their willingness to participate in the study. We are also grateful to Afar Regional Health Bureau, Awash Fentale Health Office, and Samara University for material support. Finally, our appreciation goes to data collectors for their unreserved contribution in data collection activities.

\section{Competing interests}

The authors declare that they have no competing interests.

\section{Availability of data and materials}

Data will be available upon request from the corresponding author. However, we do not need to share the data. This is because some data collected from mothers were sensitive in nature such as abortion history of mothers.

\section{Consent to publish \\ Not applicable.}

\section{Ethics approval and consent to participate}

Ethical approval was obtained from Samara University ethical review committee. Permission letter was also obtained from Afar regional Health Bureau. Official letter of co-operation was obtained from Awash Fentale health office. Respondents were briefed about the purpose and objectives of the study. Participant's privacy and confidentiality of the information were maintained. Written formal consent was obtained from each participant and from their parents/guardians for those mothers whose age less than 18 years to ensure their voluntariness to participate in the study and all participants had a right to withdraw at any time or to skip for a single question or segment of questions she didn't want to answer or refuse to participate at all with no negative repercussion.

\section{Funding}

This study was funded by Afar Regional Health Bureau. The views presented in the article are the authors and not necessarily express the views of the funding organization. Afar Regional Health Bureau did not involve in the design of the study, data collection, analysis and interpretation.

\section{Publisher's Note}

Springer Nature remains neutral with regard to jurisdictional claims in published maps and institutional affiliations. 
Received: 24 October 2017 Accepted: 17 February 2018

Published online: 02 March 2018

\section{References}

1. World Health Organization, UNICEF, UNFPA, The World Bank. Maternal mortality in 2005: estimates developed by WHO, UNICEF, UNFPA and the World Bank. Geneva: World Health Organization; 2007.

2. CSA. Ethiopia demographic and health survey 2011. Addis Ababa: Central Statistical Agency and ICF International; 2012. p. 430.

3. Group CCW. Countdown to 2015 for maternal, newborn, and child survival: the 2008 report on tracking coverage of interventions. Lancet. 2008;371(9620):1247-58.

4. Melaku YA, Weldearegawi B, Tesfay FH, Abera SF, Abraham L, Aregay A, Ashebir Y, Eshetu F, Haile A, Lakew Y. Poor linkages in maternal health care services - evidence on antenatal care and institutional delivery from a community-based longitudinal study in Tigray region, Ethiopia. BMC Pregnancy Childbirth. 2014;14(1):418.

5. Fikre AA, Demissie M. Prevalence of institutional delivery and associated factors in Dodota Woreda (district), Oromia regional state, Ethiopia. Reprod Health. 2012;9(1):33.

6. Amdemichael R, Tafa M, Fekadu H. Maternal satisfaction with the delivery services in Assela Hospital, Arsi zone, Oromia region. Gynecol Obstet (Sunnyvale). 2014;4(257):2161. https://doi. org/10.4172/2161-0932.1000257.

7. CSA. Ethiopian Mini Demographic and Health Survey. Addis Ababa: Central Statistical Agency; 2014

8. FMOH U, UNFPA, WHO, AMDD. National baseline assessment for emergency obstetric and newborn care in Ethiopia, 2008. Addis Ababa: The Ethiopian federal Ministry of health; 2009.

9. Kamal SM. Preference for institutional delivery and caesarean sections in Bangladesh. J Health Popul Nutr. 2013;31(1):96-109.

10. CSA. The EDHS Program, 2016. Addis Ababa: Central Statistical Agency and ICF International; 2017.

11. Mekonnen MG, Yalew KN, Umer JY, Melese M. Determinants of delivery practices among Afar pastoralists of Ethiopia. Pan Afr Med J. 2012;13(Suppl 1):17. https://doi.org/10.11604/pamj.supp.2012.13.1.2066.

12. Awash Fentale District Finance and Economic Development Office. Population Estimation Report; 2016.

13. Amano A, Gebeyehu A, Birhanu Z. Institutional delivery service utilization in Munisa Woreda, South East Ethiopia: a community based cross-sectional study. BMC Pregnancy Childbirth. 2012;12(1):105

14. Hagos SSD, Assegid M, Mekonnen A, Afework MF, Ahmed S. Utilization of institutional delivery service at Wukro and Butajera districts in the Northern and South Central Ethiopia. BMC Pregnancy Childbirth. 2014;14(1):178.
15. Alemayehu Sayih EG. Factors determining choice of delivery place among women's of child bearing age in Dega Damot Woreda. Ethiopia: Amhara Regional State; 2014

16. Eyob B, Worku A. Factors associated with utilization of institutional delivery among mothers in the Butajera Health \& Demographic Surveillance System, Ethiopia. 2013. http://etd.aau.edu.et/bitstream/123456789/5895/1/Bezawit\%20Eyob\%20final\%20thesis.pdf.

17. Esena RK, Sappor M-M. Factors associated with the utilization of skilled delivery services in the Ga East Municipality of Ghana Part 2: barriers to skilled delivery. Int J Sci Tech Res. 2013;2(8):195-207.

18. Abeje G, Azage M, Setegn T. Factors associated with Institutional delivery service utilization among mothers in Bahir Dar City administration, Amhara region: a community based cross sectional study. Reprod Health. 2014;11(1):22

19. Awoke W, Muhammed J, Abeje G. Institutional delivery service utilization in Woldia. Ethiop Sci J Public Health. 2013;1(1):18-23.

20. CSA. The DHS program 2016. Addis Ababa: Central Statistical Agency and ICF International; 2017.

21. Exavery A, Kanté AM, Njozi M, Tani K, Doctor HV, Hingora A, Phillips JF. Access to institutional delivery care and reasons for home delivery in three districts of Tanzania. Int J Equity Health. 2014;13(1):48.

22. Teferra AS, Alemu FM, Woldeyohannes SM. Institutional delivery service utilization and associated factors among mothers who gave birth in the last 12 months in Sekela District, North West of Ethiopia: a communitybased cross sectional study. BMC Pregnancy Childbirth. 2012;12(1):74.

23. Zegeye K, Gebeyehu A, Melese T. The role of geographical access in the Utilization of institutional delivery service in rural Jimma Horro District, Southwest Ethiopia. Prim Health Care. 2014;4(1):2167. https://doi. org/10.4172/2167-1079.1000150.

24. Wolelie A, Aychiluhm M, Awoke W. Institutional delivery service utilization and associated factors in Banja District, Awie Zone, Amhara Regional Sate, Ethiopia. Open J Epidemiol. 2014;4(01):30.

25. Idris S, Gwarzo U, Shehu A. Determinants of place of delivery among women in a semi-urban settlement in Zaria, northern Nigeria. Ann Afr Med. 2006;5(2):68-72

26. Feyissa TR, Genemo GA. Determinants of institutional delivery among childbearing age women in Western Ethiopia, 2013: unmatched case control study. PLoS ONE. 2014;9(5):e97194.

27. Kidanu S, Degu G, Tiruye TY. Factors influencing institutional delivery service utilization in Dembecha district, Northwest Ethiopia: a community based cross sectional study. Reprod Health. 2017;14(1):98.

\section{Submit your next manuscript to BioMed Central and we will help you at every step:}

- We accept pre-submission inquiries

- Our selector tool helps you to find the most relevant journal

- We provide round the clock customer support

- Convenient online submission

- Thorough peer review

- Inclusion in PubMed and all major indexing services

- Maximum visibility for your research

Submit your manuscript at www.biomedcentral com/submit
C Biomed Central 